\title{
Correction to: Designing and Modeling of Multi-epitope Proteins for Diagnosis of Toxocara canis Infection
}

\author{
Maryam Ebrahimi ${ }^{1}$ - Seyyed Javad Seyyedtabaei ${ }^{2} \cdot$ Mohammad Mehdi Ranjbar $^{3} \cdot$ Farid Tahvildar-biderouni $^{2}$. \\ Amirreza Javadi Mamaghani ${ }^{2}$
}

Published online: 8 November 2019

๑) Springer Nature B.V. 2019

\section{Correction to: \\ International Journal of Peptide Research and Therapeutics https://doi.org/10.1007/s10989-019-09940-1}

The original version of this article unfortunately contained an error in the co-author name and also the Acknowledgement section was not included.

The author name should be Amirreza Javadi Mamaghani instead it was published incorrectly as Amir Javadi-Mamaghani.

The Acknowledgements section is given below:
Acknowledgements This article has been extracted from the thesis written by Mrs/Mr Maryam Ebrahimi in School of Medicine Shahid Beheshti University of Medical Sciences. (Registration No: 515).

The original article has been corrected.

Publisher's Note Springer Nature remains neutral with regard to jurisdictional claims in published maps and institutional affiliations.
The original article can be found online at https://doi.org/10.1007/ s10989-019-09940-1.

\section{Seyyed Javad Seyyedtabaei}

Seyyedtabaei@gmail.com; seyyedtabaei@sbmu.ac.ir

1 Department of Medical Parasitology and Mycology, School of Medicine, Student Research Committee, Shahid Beheshti University of Medical Sciences, Tehran, Iran

2 Department of Medical Parasitology and Mycology, School of Medicine, Shahid Beheshti University of Medical Sciences, Tehran, Iran

3 Department of Immunology, Razi Vaccine and Sera Research Instute, Karaj, IR, Iran 